\title{
Crimes e pecados: Woody Allen, Hollywood e o cinema independente
}

\author{
Marcos Soares \\ Ana Paula B. Anjos \\ Marcos Fabris*
}

\section{Resumo}

Este ensaio traz uma análise do filme Crimes e Pecados (1989) do cineasta Woody Allen que enfatiza suas reflexões tanto sobre a situação do cinema independente no final dos anos 80 nos Estados Unidos quanto sobre as condições de possibilidade de sua própria carreira.

Palavras-chave

Woody Allen. Cinema independente. Renascença americana.

Praticamente a totalidade da crítica levou a sério os problemas existenciais de Judah Rosenthal, o protagonista do filme Crimes and Misdemeanors (1989), um dos mais celebrados do cineasta Woody Allen. A partir da cena do jantar em que o pai e a tia de Judah debatem a existência de Deus e o sentido da existência, entre outros temas de envergadura semelhante, grande parte dos críticos concentrou-se nas reflexões sobre os conteúdos "filosóficos" do filme ${ }^{1}$, em geral ignorando que o registro da cena não é naturalista, mas faz parte de um acerto de contas que um assassino e estelionatário faz consigo mesmo para justificar o salve-se quem puder que garante sua vida de riqueza e privilégios. Entretanto, o engano é, pelo menos em parte, compreensível, pois o filme de fato faz um aproveitamento, cujo alcance crítico é

\footnotetext{
* Marcos Soares é professor de literatura Norte-Americana da Faculdade de Filosofia, Letras e Ciências Humanas da Universidade de São Paulo; Ana Paula B. Anjos é doutoranda na Faculdade de Filosofia, Letras e Ciências Humanas da Universidade de São Paulo; Marcos Fabris é professor de História da Fotografia e História da Arte e doutor pela Faculdade de Filosofia, Letras e Ciências Humanas da Universidade de São Paulo.

1 Ver, por exemplo, Sander H. Lee, Woody Allen's Angst: Philosophical Commentaries on his Serious Films. Jefferson \& London: McFarland, 1997; Foster Hirsch, Love, Sex, Death and the Meaning of Life - The Films of Woody Allen. Cambridge (MA): Da Capo Press, 2001; Peter J. Bailey. The Reluctant Film Art of Woody Allen. Kentucky: The University Press of Kentucky, 2001; Sam B. Girgus. The Films of Woody Allen. Cambridge: Cambridge University Press, 2002; Mark T. Conard \& Aeon J. Skoble (eds.). Woody Allen and Philosophy. Chicago: Open Court, 2004; Charles L. P. Silet (ed.). The Films of Woody Allen - Critical Essays. Toronto \& Oxford: The Scarecrow Press, 2006.
} 
preciso determinar, da tendência de parte da dramaturgia moderna e de certo tipo de cinema de alçar a dimensões trágicas os problemas de gente ilustre e endinheirada ${ }^{2}$. Some-se a isso a discussão (necessariamente séria) sobre os traumas causados pelo holocausto nazista, um dos temas da conversa entre o pai e a tia, e temos delineada uma situação que, se não percebida como armadilha, pode levar a uma identificação perigosa com as justificativas que Judah enuncia e incorpora.

Além disso, o filme apresenta outro problema interpretativo, ainda relacionado ao anterior, mas desta vez de caráter mais propriamente estrutural: se a ênfase da narrativa está nas crises que pontuam a trajetória de Judah, como explicar a inserção da linha "cômica" que caracteriza a história de Clifford? Como, afinal, conciliar o elemento auto-reflexivo que marca as atribulações de um cineasta "sério", forçado a fazer um filme sobre o cunhado medíocre e bem sucedido, com as reflexões filosóficas do primeiro enredo? Naturalmente, insistir, como fez o próprio cineasta ${ }^{3}$, que a intenção era fazer um experimento a partir das interações entre a tragédia e a comédia não resolve a questão, mas apenas cria outro problema interpretativo. De outro lado, a saída de grande parte da crítica de apontar que o segundo núcleo narrativo funciona como mero interlúdio cômico que amplia e confirma as dimensões metafísicas do primeiro ao enfatizar a questão da traição amorosa e profissional não apenas repõe a divisão (frequentemente ideológica) entre tragédia (séria) e comédia (leve), mas também resvala para um nível de generalização que ignora boa parte do material mobilizado pelo filme, principalmente no que tange sua radiografia mordaz dos mecanismos da indústria cultural.

Já a centralidade deste último assunto para os dois núcleos dramáticos pode ser verificada através da observação de pelo menos dois procedimentos formais importantes: de um lado, a passagem de um núcleo para outro é frequentemente feita através da inserção do trecho de um filme, cujo papel é duplo, pois é assistido pelos personagens em torno de Clifford (sua face diegética, visível para parte das personagens), mas comentam a ação do núcleo ao redor de Judah (sua face mais propriamente épica, visível apenas para o espectador); de outro, a união dos dois enredos, na última sequência do filme, quando Judah e Clifford finalmente se encontram, tem como tema explícito as reflexões de ambos a respeito das convenções dos filmes hollywoodianos e sua relação com a "vida real".

Entretanto, não é preciso esperar tanto para ser introduzido pelo filme no universo da representação dramática: já a primeira cena, quando Judah recebe um prêmio por suas ações filantrópicas, tem natureza claramente "teatral". A filmagem em profundidade de campo e a trilha sonora enfatizam a presença do público e seus aplausos, enquanto o nervosismo do protagonista é descrito por sua esposa como "stage-fright" (ou seja, o receio ou fobia de atuar perante uma determinada plateia). A atuação em curso no "palco" é denunciada pelo flashback do personagem, que situado fora do campo visível da cena para os espectadores do discurso filantrópico, funciona como "bastidor", revelando sem rodeios o verdadeiro motivo do nervosismo (a carta

\footnotetext{
${ }^{2}$ Ver, sobre essa questão, a reflexão mais ampla de Raymond Williams em Tragédia Moderna (1966), São Paulo: Cosac Naify, 2002.

${ }^{3}$ Ver Stig Björkman. Woody Allen on Woody Allen. New York: Grove Press, 1993.
} 
da amante Dolores endereçada à esposa e interceptada por Judah horas antes da cerimônia). Mais tarde descobriremos (através da mesma Dolores) que a ação filantrópica, objeto dos aplausos entusiasmados da plateia e dos elogios rasgados tanto ao businessman quanto ao esmerado pai de família, é apenas pretexto para encobrir as perdas financeiras de Judah no mercado de investimentos. Assim, o filme introduz dois tipos de público estruturalmente equivalentes, mas, ao mesmo tempo, insiste em sua disjunção: enquanto o primeiro, interno ao filme, tem acesso apenas aos dados imediatamente apreensíveis da encenação, o segundo, composto pelos espectadores, tem acesso à totalidade das informações através do recurso ao flashback e à montagem. Constrói-se, assim, um mecanismo narrativo que opõe verdade e obscurantismo, aparência e essência, presente e rememoração e que será uma das chaves interpretativas do filme, dando nova densidade à metáfora desgastada da visibilidade/cegueira. Digamos, para adiantar a discussão, que Crimes e Pecados vai justamente desmascarar a ideologia do estilo "invisível" do filme hollywoodiano, ao demonstrar que a relação entre esse tipo de filme e a vida social é uma relação de seleção, transformação, apagamento e falsificação de materiais.

A partir dessa sequência inicial, o filme insistirá, como apontado acima, na comparação entre diversas sequências de filmes hollywoodianos e a história de Judah, revelando na trajetória do protagonista parte do material que geralmente fica de fora nos filmes cujos temas são as intrigas amorosas (como em Mr and Mrs Smith de Alfred Hitchcock, 1941) ou os assassinatos das pessoas que atrapalham a trajetória triunfante do herói dramático (como em This Gun for Hire, clássico noir de Frank Tuttle de 1942). Assim como a fala de Judah que abre o filme "reprime" a carta de Dolores e coloca em seu lugar o falso discurso filantrópico e religioso, cada uma das sequências desse primeiro núcleo narrativo se estruturará a partir da dicotomia entre o ritual social sem sentido (as festas, o jantar com os amigos, a comemoração do aniversário, a vida familiar e profissional, os esforços filantrópicos) e seu pressuposto escondido (a violência, a mentira, o autoengano, o roubo, o assassinato), construindo uma oposição não entre o espaço da liberdade e o espaço da restrição, mas entre dois tipos de claustrofobia: a repetição insuportável da vida cotidiana (cujo símbolo mais eloquente é a esteira dada pela família a Judah como presente de aniversário, que combina reiteração e narcisismo) e o retorno do reprimido na forma da memória indesejável, que transforma a possibilidade de libertação sexual em transgressão moral, o arejamento da rua e da praia no espaço claustrofóbico do apartamento e do carro de Dolores, a beleza da música de Schubert em presente ameaçador, o irmão em gangster, o filantropo em estelionatário, a contravenção ("misdemeanor", parte do título original do filme) em crime. Esse remanejamento radical é figurado através de uma homogeneidade de estilo que marca esse núcleo narrativo, presente principalmente no uso peculiar da fotografia, cujos tons em vermelho e amarelo reforçam a clausura dos ambientes fechados, dando a ver o correspondente visual da fantasmagoria e do caráter artificial e asfixiante da consciência de Judah.

Ao mesmo tempo essa consciência realiza uma auto-análise de seus pressupostos, num processo que se aproxima da prática psicanalítica (a mesma que Judah recomenda a Dolores num momento de desespero) em que hipóteses são levantadas e testadas, rejeitadas ou aceitas. As cenas centrais neste caso são 
justamente aquelas em que se mesclam flashes capturados do fluxo da memória (os rituais religiosos da infância, os encontros mais felizes com Dolores), confissões (na conversa com o rabino Ben) e visões noturnas, reelaboradas em seguida nos momentos em que essa consciência recupera, pelo menos em parte, personagens e eventos da "vida real" e as transforma, conforme seus desideratos, numa expressão perversa do fluxo de consciência que havia caracterizado a "riqueza psíquica" das personagens modernistas. Assim, duas conversas, uma com Ben no consultório, outra com Jack, o irmão gangster, na beira da piscina, são retomadas na sala de Judah durante uma tempestade, antes do telefonema que selará o destino de Dolores: aqui os diálogos originais são "reescritos" e misturados na imaginação para demonstrar a superioridade da visão de Jack (mais próximo da "vida real") em relação à inevitável ingenuidade do rabino (um cego que realmente não vê), com sua crença na existência de uma estrutura moral que garanta a justiça das decisões humanas. Do mesmo modo, a cena do jantar-ritual familiar é composta pelo trabalho de rememoração de momentos da infância a serviço da justificativa do presente: as duas posições contrárias - a do pai, que "prefere Deus à verdade" e a da tia, que acredita que aquilo que chamamos de padrão moral é formado pela visão dos vencedores da História são encenadas para serem "superadas" por uma nova combinação, inusitada e explosiva: são negados o poder regulador da religião (pai) e o desejo de contraposição à visão hegemônica da História (tia) e são aceitos a negação da verdade, o eterno relativismo e o darwinismo social (Judah).

Mas não são esses valores que, em sua ênfase no elogio à trajetória do vencedor, constituem o centro do cinema dramático e hegemônico? Saem de cena os filmes que no final dos anos 60 e início dos 70 (momento da chamada Renascença Americana, quando Woody Allen inicia sua carreira) haviam feito uma radiografia da vida dos "losers" americanos e entram os representantes da "ética do sucesso" que marcaria a vida ideológica da década de 80 e grande parte do cinema americano produzido na era Reagan. Entram aqui, então, as figuras de Lester, realização desse princípio no mundo do espetáculo, e de Clifford, sua contraposição. É na figura deste último, interpretado pelo próprio Woody Allen, que se adensam os problemas interpretativos do filme. Pois seu gosto pelos filmes antigos tem feição francamente escapista, enquanto seu trabalho como cineasta pode aparentar um ânimo raro, cuja face mais eloquente estaria no filme que faz sobre Lester, que não deixa pedra sobre pedra no tratamento de seu assunto. A investigação sobre o que parece ser uma contradição deve começar com uma análise detida do emaranhado de fatores que compõem essa questão.

De um lado, temos o gosto pelo glamour da Hollywood dos anos 40-50: é Clifford que assiste com ardor de cinéfilo aos filmes que fazem a transição entre os núcleos narrativos, em geral na companhia da sobrinha ou de Hallie, a produtora independente, que participam de seu processo de "educação sentimental". A saída da sala de projeção o lança de volta a um mundo hostil, distante da Nova York antiga, que só pode ser vislumbrada no livro de fotos da cidade dado de presente à sobrinha. Já de volta ao apartamento da irmã, Clifford, cujos filmes abordam temas pouco festivos como a radiação tóxica e a leucemia, mostra que na vida real a situação é de outra ordem: ao ouvir a história de uma aventura sexual grotescamente mal sucedida, 
tem contorções incontroláveis de repúdio. É de uma perspectiva nostálgica e escapista que se monta sua insatisfação com o mundo: o embate contra a figura de Lester se dá, assim, em nome de um ideal de beleza perdido e contra a imbecilidade da vida e da indústria cultural modernas. O erro do diagnóstico é evidente: não apenas na valorização do glamour do passado (resultado do apagamento sistemático que Hollywood fez das agruras dos anos da Depressão, da guerra e do macarthismo nas décadas de 40 e 50), mas principalmente na criação de uma oposição imaginária como antídoto contra a "nova vulgaridade" da vida e do cinema atuais. Não é acaso, portanto, que um dos filmes favoritos de Clifford seja Cantando na Chuva (Singing in the Rain, Stanley Donen \& Gene Kelly, 1952): pois de todos os gêneros clássicos da indústria norte-americana, o musical é aquele que mais radicalmente marca convenções internas próprias (a passagem do diálogo para o canto e a dança), que perdem a validade no embate com a vida real. Entretanto, será que Ihe passará despercebido o conteúdo mais crítico do filme, ou seja, sua exposição das maquinações falsas de Hollywood a partir da encenação da desonestidade de uma atriz do cinema mudo, que só pode manter seu falso glamour ao posar de cantora enquanto é dublada por alguém nos bastidores?

$\mathrm{Na}$ verdade, até certo ponto, o filme registra a produtividade da posição de Clifford: Lester é, de fato, uma figura nefasta que merece o tratamento dispensado no documentário; por outro lado, o filme parece pedir nossa aprovação do outro projeto em curso, o filme sobre o filósofo Louis Levy, cujas entrevistas pontuam a história. Porém, os esforços de Clifford rapidamente alcançam limites específicos, a saber, aqueles impostos tanto pelo circuito da produção independente quanto da televisão pública nos Estados Unidos dos anos 80.

Para entender este ponto, vale aqui uma curta digressão: para a totalidade dos cineastas trabalhando no final dos anos 80 os momentos que marcavam a ascensão da "Nova Hollywood" já estavam perfeitamente claros. Para encurtar a história: a função histórica de grande parte dos cineastas que surgiram na "Renascença Americana" do final dos anos 60 e início dos 70 já havia sido devidamente cumprida, isto é, salvar a indústria de sua pior crise a partir do desmonte e da disponibilização das conquistas do cinema europeu de arte para os interessados em enriquecer o cinema narrativo hegemônico através da adoção das formas da moda da arte rebelde da década anterior ${ }^{4}$. Agora essa mesma indústria podia passar para a fase de aniquilamento desses mesmos cineastas, muitos dos quais viram suas carreiras exterminadas no período ${ }^{5}$. Assim chegava ao fim boa parte da experimentação que marcara as duas décadas anteriores, tanto do ponto de vista das novas formas estéticas quanto das novas formas de produção independente, para ressurgir revigorada uma nova fase do sistema de estúdio em sua fase blockbuster, reforçado pelas políticas de desregulamentação de Reagan. Já a produção dita independente, que contava com os

\footnotetext{
${ }^{4}$ Alguns dos filmes mais representativos do período são Bonnie e Clyde - Uma Rajada de Balas (Bonnie and Clyde, 1967, Arthur Penn); A Primeira Noite de um Homem (The Graduate, 1967, Mike Nichols); Sem Destino (Easy Rider, 1969, Dennis Hopper); Perdidos na Noite (Midnight Cowboy, 1969, John Schlesinger); Meu Ódio Será Sua Herança (The Wild Bunch 1969, Sam Peckinpah), entre outros. O primeiro filme importante de Woody Allen é Um Assaltante Bem Trapalhão (Take the Money and Run, 1969).

${ }^{5}$ Para mais informações ver David Cook. Lost Illusions, New York: Scribner, 2000.
} 
cinemas de arte e repertório das grandes cidades para ser exibida, viu esse circuito praticamente desaparecer com o surgimento dos cinemas multiplexes (o cinema da Bleecker Street, onde Clifford passa parte de suas tardes, foi uma das vítimas desse processo em 1990) e se viu confinada aos festivais de cinema (os mesmos em que Clifford exibe seus filmes). Esses, por outro lado, em grande parte tomaram o Festival de Sundance (aberto em 1989) como modelo e se transformaram em vitrines para a exibição do trabalho de jovens cineastas cujo objetivo era trabalhar em Hollywood. ${ }^{6}$

Se nos circuitos cinematográficos, a carreira de Clifford tem, portanto, pouca chance de decolar, já as trajetórias de Lester e Hallie demonstram de modo inequívoco os critérios mercadológicos da produção independente na televisão pública nos Estados Unidos (o programa sobre Lester é feito para a PBS, a rede de televisão pública). Em ambos os casos a formação política e estética é, em teoria, de "esquerda": uma das novas séries de Lester sobre um casal de advogados tentará abordar "assuntos sérios" de modo "equilibrado", mas, como a atriz-modelo que o acompanha a uma das festas afirma, o programa provavelmente "terá uma tendência de esquerda". Entretanto, suas "teorias" sobre a comédia, ensinadas até em Harvard, se aproximam mais de um supermercado pós-moderno, que através de "distanciamento histórico" pode transformar tudo (de Édipo ao assassinato de Lincoln) em lixo cultural palatável. Hallie, por sua vez, quer que Lester produza uma série com uma história de Chekhov por semana. Por outro lado, seus planos de filmar Gabriel Garcia Marquez são abandonados em favor de Lester, um "grande herói americano", enquanto o projeto com Levy deve "afirmar o lado positivo de sua visão de mundo" para ter alguma chance de ser produzido. O filme aponta, assim, para a convergência entre as ideologias do filme hollywoodiano e dos chamados circuitos alternativos. É por essa razão que o suicídio do filósofo, ao instaurar uma "contradição" entre teoria e prática, produz um problema insuperável e deve ser descartado: digamos que, diante da truculência dos processos sociais modernos, a visão otimista do filósofo, assim como a do rabino, é mercadoria ultrapassada. Já a trajetória pessoal de Hallie deixa pouca dúvida sobre seus supostos princípios artísticos: como ela mesma afirma, ela nunca diz "não" para champanhe e caviar, é ambiciosa e dormir com o "inimigo" pode significar financiamento para seus futuros projetos pessoais.

Apenas o filme de Clifford sobre Lester tem ainda alguma aparência de enfrentamento. Com sua estética agressivamente militante, baseada em cortes abruptos, comparações inusitadas, descompassos entre som e imagem, sobreposições e descontinuidades, remete aos paradigmas do filme político europeu, mais próximo do agit-prop do que do estilo "invisível" e inócuo que marca a produção comercial. Por outro lado, sua investigação dos bastidores do trabalho de Lester (no momento do assédio à aspirante a atriz ou do surto de violência contra seu time de escritores) entra em consonância com um dos temas centrais do filme, produzindo um momento de visibilidade dos pressupostos que marcam o regime de trabalho da indústria cultural. Embora vejamos apenas um pequeno trecho do filme, ele mostra com eloquência o poder de fogo de Clifford (e, por extensão, de Woody Allen).

\footnotetext{
6 Para uma reflexão sobre o impacto dos festivais de cinema e especialmente do festival de Sundance sobre a produção independente americana nos anos 80-90 ver Jake Horsley, Dogville vs Hollywood - The war between independent film and mainstream movies. London: Marion Boyars Publishers, 2005 e Peter Biskind, Down and Dirty Pictures - Miramax, Sundance and the Rise of Independent Film. New York: Simon \& Schuster, 2004.
} 
Entretanto, a estratégia é desastrada e produz seu próprio aniquilamento: como era de se esperar, o filme é vetado e o diretor demitido (como a própria Hallie afirma, ela mesma poderia ter avisado Clifford sobre o perigo: afinal, além de produtora, ela também é advogada). No universo das avaliações "inocentes" que tantos personagens do filme emitem devemos adicionar a de Clifford, que reconhece de modo imperfeito seu lugar como trabalhador. É nesse momento que a confluência, mas também a diferença, entre Clifford e Woody Allen revela seu lado mais produtivo e nada inocente: pois no personagem, Woody Allen mostra aquilo que ele mesmo deve evitar se desejar sobreviver na indústria.

Curiosamente, Woody Allen praticamente não aparece nos estudos críticos da "Renascença Americana", de quem ele é contemporâneo. Num desses estudos, o autor resume a atitude geral de modo exemplar:

Há um cineasta "mainstream" que conseguiu manter sua independência e autonomia dentro do sistema e que aparenta indiferença tanto em relação ao sucesso comercial quanto ao gosto do público. Durante toda sua carreira, ele fez filmes exatamente do modo que quis. Sempre teve poder de decisão sobre a forma final de seus filmes (a expressão "final cut" é um termo mítico em Hollywood) e não apenas tem evitado, mas tem permanecido indiferente aos tipos de batalhas que destruíram cineastas como Peckinpah e Welles. É um verdadeiro autor de seus filmes e, entretanto, sempre fez filmes para estúdios e nunca (pelo que eu saiba) sofreu intervenção em seus filmes ou em sua visão de mundo. Como conseguiu isso? Sendo Woody Allen. [...] Desde o início, seu carisma e talento foram considerados tão claramente idiossincráticos e únicos que [os produtores] acabaram por intuir que o melhor seria não procurar restringir ou moldar seus filmes, mas simplesmente deixá-lo fazer o que quisesse e lucrar com isso ${ }^{7}$.

Na verdade, a carreira de Woody Allen desmente ponto a ponto essa sentença sobre sua suposta liberdade criativa, particularmente depois do desastre comercial de Melinda e Melinda (2004) e sua busca de financiamento na Europa. Se há algo único nessa trajetória, não se trata da liberdade das pressões comerciais, mas da adoção de estratégias inéditas e criativas (tanto no campo da produção dos filmes quanto das escolhas estéticas) que marcam sua carreira e que merecem estudo detalhado. Crimes e Pecados pode ser um bom ponto de início desse estudo, pois é uma demonstração prática de um conjunto de estratégias empregadas por Woody Allen para negociar entre as demandas do mercado e da indústria e as reivindicações de uma arte mais exigente e crítica. Essas estratégias pressupõem, dentre outras medidas, a simultânea manutenção e análise crítica de pelo menos dois procedimentos caros ao cinema hegemônico: o protagonismo e o final feliz. No primeiro caso, trata-se de manter como centro da linha dramática a questão do empreendedorismo (neste caso, de Judah), a máquina que move o enredo desde a ascensão do drama burguês, mas partir para uma exposição de seus pressupostos e resultados violentos. No segundo, trata-se de manter a aparência de certo fechamento dramático ou teleologia ao mesmo tempo em que dá ênfase aos mesmos pressupostos, mostrando a vitória do protagonista como desastre social generalizado.

\footnotetext{
7 Jake Horsley, op. cit. p. 133.
} 
Em Crimes e Pecados há um fechamento duplo. No primeiro, Judah e Clifford se encontram pela primeira vez, enquanto no segundo realiza-se a festa de casamento da filha de Ben. Novamente, como no início do filme, estabelece-se uma relação entre "cena" e "bastidor", o espaço do ritual social e aquele de seu pressuposto escondido. Nos bastidores da festa Judah conta a Clifford/Woody Allen o "enredo" da história de um crime perfeito. O diretor, alinhando-se, mesmo sem saber, com Ben, mas também com as demandas do cinema comercial, exige um fechamento trágico, talvez esperando que algum tipo de justiça divina o vingasse pela dupla traição de que fora vítima. De outro lado, Judah, mais "realista", enfatiza que "isso só acontece nos filmes" e reafirma a lógica do crime e seus laços com uma vida social bem-sucedida. A evidente "superioridade" da visão de Judah, que encara com simplicidade e realismo os dados da "vida real", sugere a naturalização de uma ordem social perversa, que permanece de pé através da execução de atos violentos que se esfumaçam no palco da vida social e cuja reiteração futura é sugerida no anúncio do casamento da filha de Judah. Já Clifford, o artista, busca refúgio em idealizações cuja face social mais visível é o filme hollywoodiano.

O "final feliz" fica por conta do retorno à festa de casamento e à dança da filha com o rabino. O tom afirmativo está presente na fala de Levy, em voz-over, que reafirma a ordem do universo e a esperança de que as futuras gerações possam aprender com os desastres do presente. Entretanto, a montagem final, que reconta em parte a história do filme, faz uma seleção nada inocente, privilegiando momentos chave da trajetória que levou ao assassinato, dentre eles os encontros com Dolores e a conversa com o irmão. Se há chance de aprendizado futuro, pelo menos no campo da arte, ela parece estar na habilidade - que o cinema exigente deve ajudar a desenvolver - de ler nas entrelinhas de todas as narrativas que afirmem a visão da história dos vencedores.

Realizado no ano da queda do muro de Berlim e no primeiro ano da era Bush, Crimes e Pecados está situado no fim da "era ideológica", na qual as elites ainda se preocupavam em manter a pose de dignidade enquanto a direita realizava nos bastidores os desmonte do Estado de bem-social em nome do grande capital. Quando até essa necessidade começou a desaparecer, Woody Allen se viu na obrigação de reatualizar seu "herói" - o Chris Wilton de Match Point será um retrato ainda mais aterrador do empreendedorismo moderno.

\section{Bibliografia}

BAILEY, Peter J. The Reluctant Film Art of Woody Allen. Kentucky: The University Press of Kentucky, 2001.

BISKIND, Peter. Down and Dirty Pictures - Miramax, Sundance and the Rise of Independent Film. New York: Simon \& Schuster, 2004.

BJÖRKMAN, Stig. Woody Allen on Woody Allen. New York: Grove Press, 1993.

CONARD, Mark T. \& SKOBLE, Aeon J. (eds.). Woody Allen and Philosophy. Chicago: Open Court, 2004. 
COOK, David. Lost Illusions. New York: Scribner, 2000.

HIRSCH, Foster. Love, Sex, Death and the Meaning of Life - The Films of Woody Allen. Cambridge (MA): Da Capo Press, 2001

HORSLEY, Jake. Dogville vs Hollywood - The war between independent film and mainstream movies. London: Marion Boyars Publishers, 2005.

GIRGUS, Sam B. The Films of Woody Allen. Cambridge: Cambridge University Press, 2002.

LEE, Sander H. Woody Allen's Angst: Philosophical Commentaries on his Serious Films. Jefferson \& London: McFarland, 1997.

SILET, Charles L. P. (ed.). The Films of Woody Allen - Critical Essays. Toronto \& Oxford: The Scarecrow Press, 2006.

WILLIAMS, Raymond. Tragédia moderna. São Paulo: Cosac Naify, 2002.

\section{Title}

Crimes and sins: Wood Allen, Hollywood and the independent cinema

\section{Abstract}

In this essay we propose an analysis of the film Crimes and Misdemeanors (1989) by Woody Allen in an attempt to focus on its reflections both on the American independent movie production in the 80 's as well as on the conditions of possibility of Allen's career.

\section{Keywords}

Woody Allen. Independent cinema. American renaissance.

Recebido em 15/01/2012. Aprovado em 28/06/2012. 